\title{
Multiple Hydrogen Kinetic Isotope Effects for Enzymes Catalyzing Exchange with Solvent: Application to Alanine Racemase
}

\author{
M. Ashley Spies and Michael D. Toney* \\ Department of Chemistry, University of California, Davis, Davis, California 95616
}

Received December 20, 2002; Revised Manuscript Received February 13, 2003

\begin{abstract}
Alanine racemase catalyzes the pyridoxal phosphate-dependent interconversion of the D- and L-isomers of alanine. Previous studies have shown that the enzyme employs a two-base mechanism in which Lys39 and Tyr265 are the acid/base catalysts. It is thus possible that stereoisomerization of the external aldimine intermediates occurs through a concerted double proton transfer without the existence of a distinct carbanionic intermediate. This possibility was tested by the application of multiple kinetic isotope effect (KIE) methodology to alanine racemase. The mutual dependence of primary substrate and solvent deuterium KIEs has been measured using equilibrium perturbation-type experiments. The conceptually straightforward measurement of the substrate $\mathrm{KIE}$ in $\mathrm{H}_{2} \mathrm{O}$ is complemented with a less intuitive protium washout perturbation-type measurement in $\mathrm{D}_{2} \mathrm{O}$. The primary substrate $\mathrm{KIE}$ in the $\mathrm{D} \rightarrow \mathrm{L}$ direction at $25{ }^{\circ} \mathrm{C}$ is reduced from 1.297 in $\mathrm{H}_{2} \mathrm{O}$ to 1.176 in $\mathrm{D}_{2} \mathrm{O}$, while in the $\mathrm{L} \rightarrow \mathrm{D}$ direction it is reduced from 1.877 in $\mathrm{H}_{2} \mathrm{O}$ to 1.824 in $\mathrm{D}_{2} \mathrm{O}$. Similar reductions are also observed at $65^{\circ} \mathrm{C}$, the temperature to which the Bacillus stearothermophilus enzyme is adapted. These data strongly support a stepwise racemization of stereoisomeric aldimine intermediates in which a substrate-based carbanion is an obligatory intermediate. The ionizations observed in $k_{\text {cat }} / K_{\mathrm{M}} \mathrm{pH}$ profiles have been definitively assigned based on the $\Delta H_{\text {ion }}$ values of the observed $\mathrm{p} K_{\mathrm{a}}$ 's with alanine and on the $\mathrm{pH}$ dependence of $k_{\mathrm{cat}} / K_{\mathrm{M}}$ for the alternative substrate serine. The acidic $\mathrm{p} K_{\mathrm{a}}$ in the bell-shaped curve is due to the phenolic hydroxyl of Tyr265, which must be unprotonated for reaction with either isomer of alanine. The basic $\mathrm{p} K_{\mathrm{a}}$ is due to the substrate amino group, which must be protonated to react with Tyr265-unprotonated enzyme. A detailed reaction mechanism incorporating these results is proposed.
\end{abstract}

Bacterial cell walls are rigid structures consisting of polysaccharides cross-linked with peptides (1). They provide protection from osmotic lysis, and thus their biosynthetic pathways are attractive targets for antibiotic development. The peptide component of peptidoglycan contains D-amino acids such as D-alanine and D-glutamate, which are thought to confer resistance to protease digestion (2). D-Alanine is essential in that it plays an important role both in synthesis of the primary pentapeptide and in interstrand cross-linking $(1,2)$.

There are three potential enzymatic antibacterial targets for blocking the incorporation of D-alanine into peptidoglycans: alanine racemase, D-Ala-D-Ala ligase, and ATP-dependent D-Ala-D-Ala adding enzyme $(1,2)$. Alanine racemase is a pyridoxal phosphate (PLP) ${ }^{1}$-dependent enzyme that catalyzes the first step in the D-alanine branch of peptidoglycan biosynthesis, the reversible isomerization of L- to D-alanine (3). Inhibitors of alanine racemase (4-8) have been pursued as potential antibacterial agents, although apparently no designed inhibitors have yet found clinical success. On the other hand, cycloserine, a natural product, is a good inhibitor of alanine racemase and other PLP-dependent en-

* Corresponding author. Tel: 530-754-5282. Fax: 530-752-8995. E-mail: mdtoney@ucdavis.edu.

${ }^{1}$ Abbreviations: PLP, pyridoxal 5'-phosphate; KIE, kinetic isotope effect; CD, circular dichroism; SIE, solvent isotope effect. zymes $(9-13)$, and has found wide clinical use in some applications $(14-18)$.

As with all PLP-dependent enzymes, a covalent PLPamino acid aldimine intermediate is formed in the alanine racemase mechanism, increasing the acidity of the $\mathrm{C} \alpha$ proton. Previous work has established that racemization in the Bacillus stearothermophilus enzyme takes place via a twobase mechanism, in which Tyr265 and Lys39 act as general acid/base catalysts (19-21). Tyr265 abstracts the $\mathrm{C} \alpha$ proton from the aldimine formed from L-alanine (Scheme 1). Reprotonation from the opposite face, with a solvent derived proton from Lys39, yields the antipodal aldimine. In the D $\rightarrow$ L direction, Lys39 abstracts the substrate proton, while Tyr265 provides the solvent derived proton.

Racemization may take place through a distinct, delocalized PLP-amino acid carbanionic intermediate. Alternatively, the racemization may take place in a single, concerted double proton transfer, avoiding formation of a carbanionic intermediate and the development of negative charge at $\mathrm{C} \alpha$. Several observations are consistent with a concerted reaction mechanism. Many PLP-containing enzymes enhance the electron-sink capabilities of PLP by juxtaposing a highly conserved acidic residue adjacent to the pyridine nitrogen, presumably maintaining it protonated. Uniquely in alanine racemase, an arginine side chain (Arg219) hydrogen bonds to the pyridine nitrogen (22). This interaction effectively 
Scheme 1: Outline of the Alanine Racemase Mechanism Including a Carbanionic Intermediate.

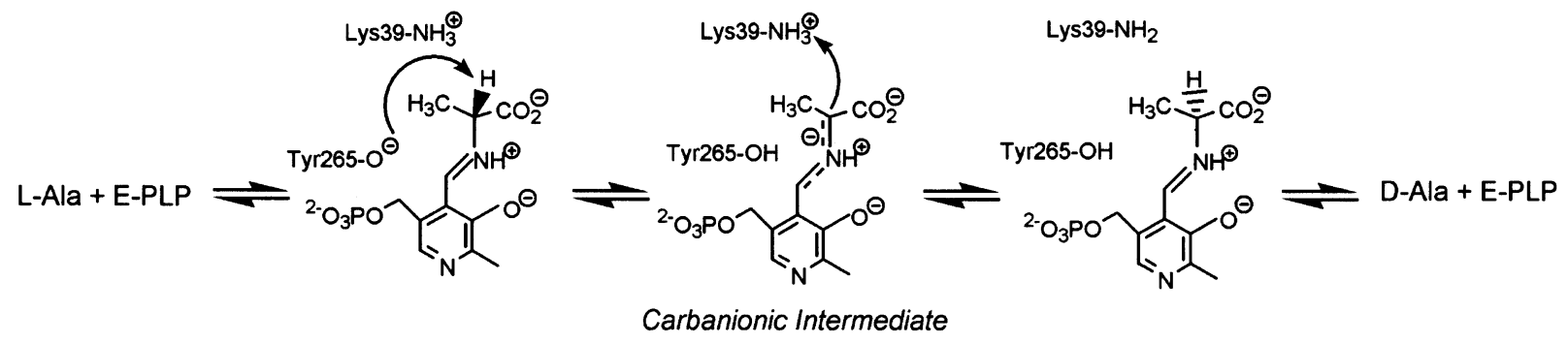

keeps the pyridine nitrogen from being formally protonated since the $\mathrm{p} K_{\mathrm{a}}$ difference between these groups is $\sim 8$ units. The lack of pyridine nitrogen protonation is expected to destabilize the carbanionic intermediate. Further support for the concerted mechanism is provided by the inability to detect spectroscopically the formation of a carbanionic quinonoid intermediate in the wild-type enzyme (19).

Multiple kinetic isotope effects (KIEs) have been widely employed to distinguish between concerted and stepwise mechanisms (23-25). Two independent KIEs must be observed prior to the application of this methodology, and the mutual dependence of these KIEs provides the diagnostic. In the case of alanine racemase, primary deuterium substrate KIEs and $\mathrm{D}_{2} \mathrm{O}$ solvent KIEs were previously measured and found to be significantly greater than unity, yet not large ( 1.5) (19). Thus, the multiple KIE diagnosis of mechanism is applicable to alanine racemase if hydrogen KIEs of high enough precision can be measured.

The equilibrium perturbation method, introduced by Cleland and co-workers for reversible enzyme catalyzed reactions (26), allows the measurement of KIEs with high precision (e.g., $\leq 1 \%$ error), and thus is attractive for $\mathrm{KIE}$ measurements on alanine racemase. Several excellent reviews of the technique are available $(27,28)$. The technique has been used to determine primary KIEs with errors as low as $0.38 \%$ (29). The equilibrium perturbation technique is particularly amenable to freely reversible systems, especially those with low $\Delta H_{0}$ values (27). Having an equilibrium constant of unity, and a $\Delta H_{0}$ value of zero, alanine racemase is particularly well suited to the equilibrium perturbation method. To obtain multiple hydrogen KIEs for alanine racemase, the current study employs "competitive hydron washout" experiments $(29,30)$, which are a type of equilibrium perturbation experiment, in both $\mathrm{H}_{2} \mathrm{O}$ and $\mathrm{D}_{2} \mathrm{O}$.

The data support a stepwise mechanism for alanine racemase at both 25 and $65{ }^{\circ} \mathrm{C}$ (the optimal growth temperature of $B$. stearothermophilus). Thus, the carbanionic intermediate is obligatory, and Arg219 may serve to destabilize it to avoid side reactions such as transamination (31). On the basis of the conclusions from the multiple KIE experiments and several $k_{\text {cat }} / K_{\mathrm{M}} \mathrm{pH}$ profiles, a detailed reaction mechanism for alanine racemase is proposed that includes enzyme and substrate protonation states.

\section{EXPERIMENTAL SECTION}

Materials. Deuterated D-alanine was purchased from CDN Isotopes (Quebec, Canada), catalog number D-1274, 98 atom $\%$. Deuterated L-alanine was purchased from Isotec, Inc. (USA), minimum 98 atom \%. Protiated D- and L-alanine were purchased from Aldrich Chemical Company (99\% pure), respectively. Deuterium oxide (99.9 atom \%) was purchased from Cambridge Isotope Laboratories Inc. The alanine racemase used in this study was prepared as described previously (19). The buffers used were from Fisher.

Amino Acid $p K_{a}$ Values. The $\mathrm{p} K_{\mathrm{a}}$ values for alanine and serine at an ionic strength of 0.125 (equal to that in the $\mathrm{pH}$ profile determinations) were determined. Solutions of $10 \mathrm{~mL}$ of $10 \mathrm{mM}$ amino acid in $125 \mathrm{mM} \mathrm{KC1}$ were titrated with 1 $\mathrm{M} \mathrm{KOH}$. The $\mathrm{p} K_{a}$ values were obtained by nonlinear regression fitting to the Henderson-Hasselbach equation. The $\mathrm{pH}$ meter was calibrated between $\mathrm{pH} 4$ and 10 .

Instrument. A Jasco 720 circular dichroism spectrometer was used for all studies. The wavelengths used in the various studies were chosen such that CD is linear with amino acid concentration, which was found to correspond to a "high tension voltage" (HTV) value below 400 V. Data acquisition was carried out using the Jasco program J-700 under the Windows Hardware Manager, version 1.10.00.

$k_{\text {cat }} / K_{M} p L$ Profiles. Buffers that are optically clear at 210 $\mathrm{nm}$ were required. Therefore, depending on the $\mathrm{pL}$, the buffers were either $50 \mathrm{mM}$ potassium borate, $100 \mathrm{mM}$ potassium chloride (between pL 8.0 and 10.9) or $50 \mathrm{mM}$ potassium phosphate, and $100 \mathrm{mM}$ potassium chloride $(\mathrm{pL}$ less than 8.0, and greater than 10.9). The $\mathrm{pH}$ of the reaction mixtures was measured before and after data collection; differences were generally less than 0.02 units, and not greater than 0.05 . The $\mathrm{pH}$ value taken after the run was used in the profiles. The $\mathrm{D} \rightarrow \mathrm{L}$ direction was followed for alanine. As outlined below, this gives $k_{\text {cat }} / K_{\mathrm{M}} \mathrm{pL}$ profiles that are equivalent to those for the $\mathrm{L} \rightarrow \mathrm{D}$ direction since the equilibrium constant for the overall reaction is one. The Michaelis-Menten equation reduces to a simple first-order kinetics equation when the concentration of substrate is much less than the value of $K_{\mathrm{M}}$. This is shown in eq 1 . Knowing

$$
v_{\mathrm{i}}=\frac{k_{\mathrm{cat}}}{K_{\mathrm{M}}}[E]_{\mathrm{t}}[S]=k_{1}^{\prime}[S]
$$

the enzyme concentration, this allows the determination of $k_{\text {cat }} / K_{\mathrm{M}}$ from progress curves that take the form of single exponentials. The case of a reversible reaction is more complicated since the back reaction must be considered in the approach to equilibrium. The rate equation for a reversible single substrate, single product enzyme catalyzed reaction is given in eq 2 (32). When the substrate and product

$$
v_{\text {net }}=\frac{V_{\mathrm{f}} \frac{[S]}{K_{\mathrm{S}}}-V_{\mathrm{r}} \frac{[P]}{K_{\mathrm{p}}}}{1+\frac{[S]}{K_{\mathrm{S}}}+\frac{[P]}{K_{\mathrm{p}}}}
$$


concentrations are kept much lower than the values of $K_{\mathrm{s}}$ and $K_{\mathrm{p}}$, respectively, then eq 2 reduces to eq 3 .

$$
v_{\text {net }}=\frac{V_{\mathrm{f}}}{K_{\mathrm{S}}}[S]-\frac{V_{\mathrm{r}}}{K_{\mathrm{P}}}[P]
$$

This has the same form as a differential rate equation for a reversible first-order mechanism, given the units of $V / K$ are $\mathrm{s}^{-1}$. This can then be integrated to give eq 4 using standard techniques (33). Here, $x$ is the extent of reaction

$$
\frac{x_{\mathrm{e}}}{x_{\mathrm{e}}-x}=e^{-\left(\frac{V_{\mathrm{f}}}{K_{\mathrm{S}}}+\frac{V_{\mathrm{r}}}{K_{\mathrm{P}}}\right) t}
$$

and $x_{\mathrm{e}}$ is the extent of reaction at equilibrium. This shows that the observed rate constant is equal to the sum of $k_{\text {cat }} / K_{\mathrm{M}}$ for the forward and reverse directions multiplied by the enzyme concentration.

Stereoisomerization has an equilibrium constant of unity that is independent of $\mathrm{pH}$. Thus, the values of $k_{\text {cat }} / K_{\mathrm{M}}$ in both directions are equal, and this equality is $\mathrm{pH}$ independent, i.e., the $\mathrm{pH}$ dependence of $k_{\mathrm{cat}} / K_{\mathrm{M}}$ is identical for both directions. What one observes here is the $\mathrm{pH}$ dependence of either of these, with the observed values of the rate constants being twice that of a single direction.

The observed values of $k_{\text {cat }} / K_{\mathrm{M}}$ (i.e., sum of the forward and reverse values) were determined from first-order fits to progress curves for racemization of $0.15 \mathrm{mM}$ D-alanine. This is at all $\mathrm{pH}$ values at least 10 -fold less than the value of either $K_{\mathrm{M}}$. The $k_{\text {cat }} / K_{\mathrm{M}} \mathrm{vs} \mathrm{pH}$ data were fitted to eq 5 , which describes a bell-shaped curve that approaches zero at the $\mathrm{pH}$ extremes. For the $25^{\circ} \mathrm{C}$ data, $\mathrm{pD}$ was calculated by adding

$$
\log \left(k_{\mathrm{cat}} / K_{\mathrm{M}}\right)=\log \left[\frac{\left(k_{\mathrm{cal}} / K_{\mathrm{M}}\right)_{\lim }}{1+10^{\left(\mathrm{p} K_{\mathrm{a}}^{1}-\mathrm{pL}\right)}+10^{\left(\mathrm{pL}-\mathrm{p} K_{\mathrm{a}}^{2}\right)}}\right]
$$

0.40 to the $\mathrm{pH}$ meter reading (34). For the $65{ }^{\circ} \mathrm{C}$ data, the observed $\mathrm{pH}$ meter reading at $65^{\circ} \mathrm{C}$ was directly plotted for both $\mathrm{H}_{2} \mathrm{O}$ and $\mathrm{D}_{2} \mathrm{O}$ solutions, since no accepted $\mathrm{H}_{2} \mathrm{O} / \mathrm{D}_{2} \mathrm{O}$ difference was found for the $\mathrm{pH}$ electrode at the higher temperature. The values of $\mathrm{pH}$ used for $65^{\circ} \mathrm{C}$ were those measured at $25^{\circ} \mathrm{C}$, given the negligible heats of ionization of the buffers used $(35,36)$. The observed values of apparent $\mathrm{pH}$ measured at $65{ }^{\circ} \mathrm{C}$ using a meter calibrated at $25{ }^{\circ} \mathrm{C}$ agreed to within $0.1 \mathrm{pH}$ units or, more generally, less with those measured at $25^{\circ} \mathrm{C}$. The enzyme concentrations were 9.2 and $4.6 \mathrm{nM}$ for 25 and $65{ }^{\circ} \mathrm{C}$, respectively. It was necessary to have $15 \mu \mathrm{M}$ PLP in the $65^{\circ} \mathrm{C}$ reaction mixture, or the enzyme is fully inactivated in approximately $10 \mathrm{~min}$. The $\mathrm{D} \rightarrow \mathrm{L}$ reaction was also followed at $65^{\circ} \mathrm{C}$.

The values of $k_{\text {cat }} / K_{\mathrm{M}}$ for the $\mathrm{pH}$ profile for serine at 25 ${ }^{\circ} \mathrm{C}$ were also obtained from exponential progress curves. The reaction of $\mathrm{L} \rightarrow \mathrm{D}$ serine was followed. The initial concentration of L-serine was $0.15 \mathrm{mM}$, which is much lower than the published value of $110 \mathrm{mM}$ at $\mathrm{pH} 9$ (37). The progress curves fit well to a first-order rate equation in all cases.

Equilibrium Perturbation-Type Washout Experiments. The wavelength of the CD instrument was set at $215 \mathrm{~nm}$ for these experiments. Mixtures containing $10 \mathrm{mM}$ each of D- and L-alanine, in a buffer composed of $50 \mathrm{mM}$ potassium borate and $100 \mathrm{mM}$ potassium chloride, were made and were checked to ensure that the optical activity was zero, as

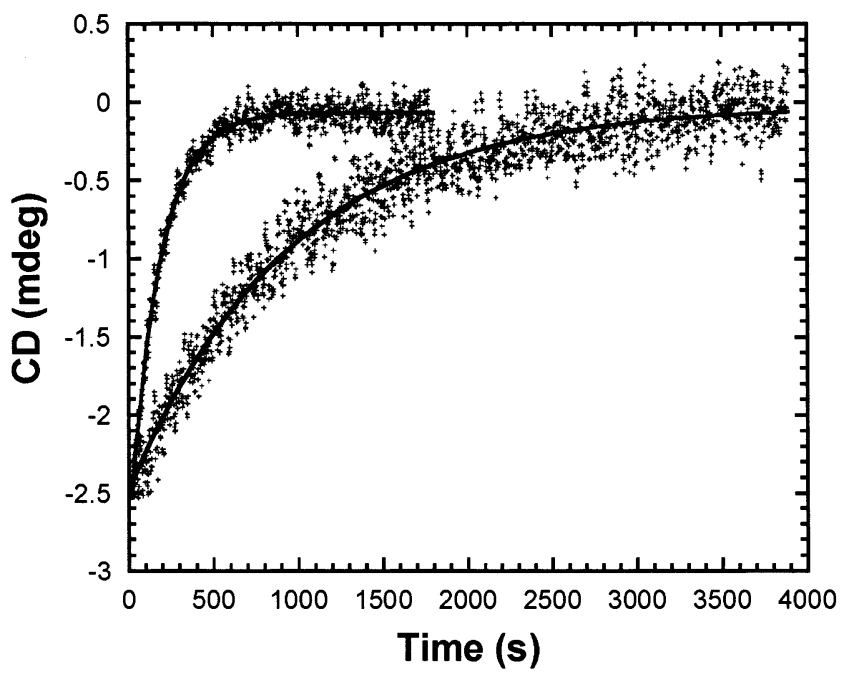

FIGURE 1: Progress curves for racemization of $0.15 \mathrm{mM}$ D-Ala at $25^{\circ} \mathrm{C}$, monitored by $\mathrm{CD}$ spectroscopy, at $\mathrm{pH} 8.0$ (upper trace) and 6.6 (lower trace). The data were fitted to a single-exponential equation to give the lines shown. The observed rate constant is equal to twice the value of $k_{\text {cat }} / K_{\mathrm{M}}$ for either direction.

expected for a racemic mixture. The enzyme was added to begin the reaction.

For $25^{\circ} \mathrm{C}$ data sets, the enzyme concentration was $54 \mathrm{nM}$. The $\mathrm{H}_{2} \mathrm{O}$ perturbations were performed at $\mathrm{pH} 8.48$, while the $\mathrm{D}_{2} \mathrm{O}$ perturbations were performed at $\mathrm{pD} 8.90$. On the basis of the $\mathrm{p} K_{\mathrm{a}}$ values observed in the $\mathrm{pH}$ profiles, this gives enzyme in equivalent protonation states, which is necessary to ensure identical commitment factors. For the $65{ }^{\circ} \mathrm{C}$ data set, the enzyme concentration was $22 \mathrm{nM}$ and the reaction mixture contained $15 \mu \mathrm{M}$ PLP. The $\mathrm{H}_{2} \mathrm{O}$ perturbations were performed at a $\mathrm{pH}$ of 8.0 , while the $\mathrm{D}_{2} \mathrm{O}$ perturbations were performed at a $\mathrm{pH}$ meter reading of 8.4 , which gives enzyme in equivalent protonation states.

The kinetic isotope effects were calculated according to Bahnson and Anderson (29). These authors give a full treatment of equilibrium perturbation-type washout kinetics and provide the equations necessary for extracting correct KIEs from experiments in which a fractionating isotope is irreversibly washed out into solvent during the course of reaction.

\section{RESULTS}

Amino Acid $p K_{a}$ Values. The $\mathrm{p} K_{\mathrm{a}}$ values for the $\alpha$-amino groups of alanine and serine were measured under the present experimental conditions so that a direct comparison to the observed $\mathrm{p} K_{\mathrm{a}}$ values from $\mathrm{pH}$ profiles could be made. The measured values are alanine, $9.94 \pm 0.02$; serine, $9.26 \pm$ 0.01 .

Progress Curve Determination of $k_{\text {cal }} / K_{M}$. Progress curves for alanine racemization are shown in Figure 1. The good fit to a single-exponential equation is evident. Equation 4 predicts that the observed rate constant is equal to twice that of $k_{\text {cat }} / K_{\mathrm{M}}$ for either direction. This was checked for $\mathrm{pH} 8.9$ data. The observed exponential rate constant divided by enzyme concentration is equal to $2.4 \pm 0.3$ times the value of $k_{\text {cat }} / K_{\mathrm{M}}$ for the $\mathrm{L} \rightarrow$ D direction obtained in initial rate experiments.

$p L$ Profiles. Figure 2A shows the $\mathrm{pH}$ and $\mathrm{pD}$ vs $\log$ $\left(k_{\text {cat }} / K_{\mathrm{M}}\right)$ profiles for D-alanine racemization, at $25^{\circ} \mathrm{C}$. Both $\mathrm{D}_{2} \mathrm{O}$ and $\mathrm{H}_{2} \mathrm{O}$ data sets exhibit a bell shaped curve, which is 

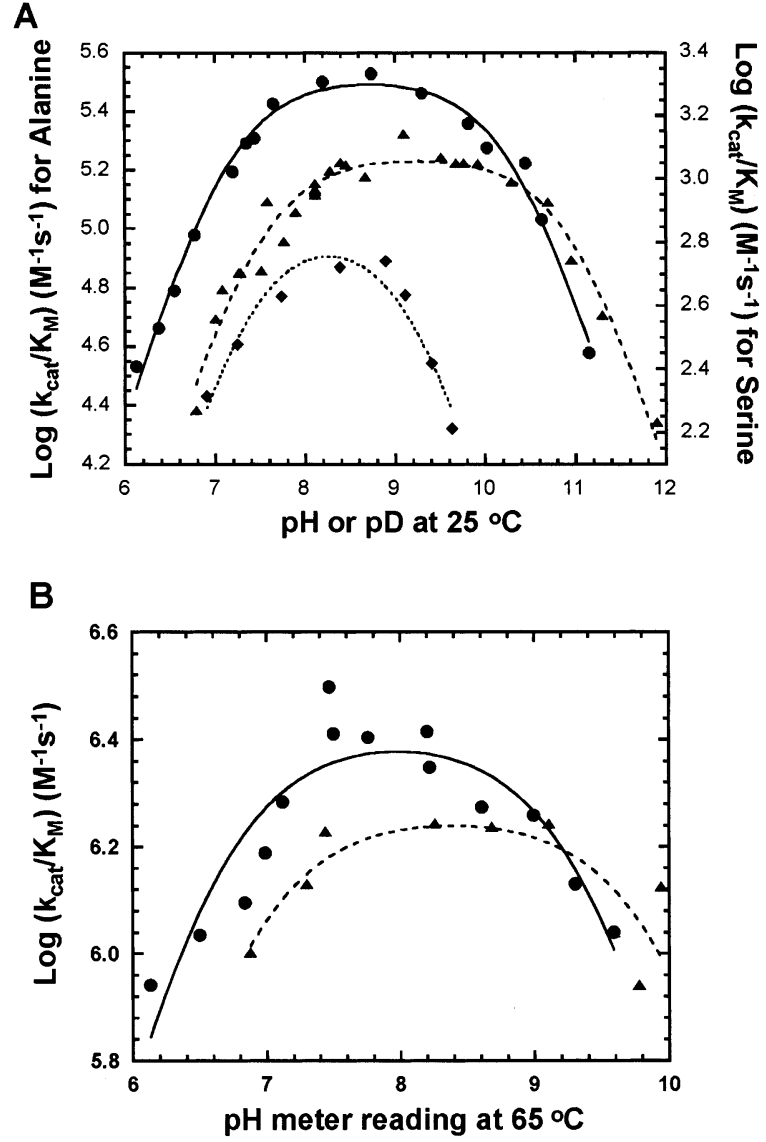

FIGURE 2: $\log \left(k_{\mathrm{cat}} / K_{\mathrm{M}}\right)$ for racemization of D- to L-alanine as a function of $\mathrm{pL}\left(\mathrm{pH}\right.$ or $\mathrm{pD}$ ) of solution. (A) $25^{\circ} \mathrm{C}$. Circles, $\mathrm{H}_{2} \mathrm{O}$; triangles, $\mathrm{D}_{2} \mathrm{O}$; diamonds, serine in $\mathrm{H}_{2} \mathrm{O}$. (B) $65^{\circ} \mathrm{C}$. Circles, $\mathrm{H}_{2} \mathrm{O}$; triangles, $\mathrm{D}_{2} \mathrm{O}$. The $\mathrm{p} K_{\mathrm{a}}$ values obtained from the fits are given in Table 1.

Table 1: Kinetic Parameters Obtained from $k_{\mathrm{cat}} / K_{\mathrm{M}} \mathrm{pH}$ Profiles ${ }^{a}$

limiting value

$\begin{array}{llll}\mathrm{pH} \text { profile } & \mathrm{p} K_{\mathrm{a}} 1 & \mathrm{p} K_{\mathrm{a}} 2 & \text { of } k_{\mathrm{cat}} / K_{\mathrm{M}}\end{array}$

alanine in $\mathrm{H}_{2} \mathrm{O}\left(25^{\circ} \mathrm{C}\right) \quad 7.14(0.04) \quad 10.31(0.05) \quad 3.24(0.16) \times 10^{5}$ alanine in $\mathrm{D}_{2} \mathrm{O}\left(25^{\circ} \mathrm{C}\right) \quad 7.48(0.05) \quad 10.99(0.06) \quad 1.75(0.07) \times 10^{5}$ alanine in $\mathrm{H}_{2} \mathrm{O}\left(65^{\circ} \mathrm{C}\right) \quad 6.56(0.11) \quad 9.41(0.13) \quad 2.56(0.21) \times 10^{6}$ serine in $\mathrm{H}_{2} \mathrm{O}\left(25^{\circ} \mathrm{C}\right) \quad 7.35(0.13) \quad 9.19(0.13) \quad 700(100)$

${ }^{a}$ Reaction conditions: $50 \mathrm{mM}$ buffer, $100 \mathrm{mM} \mathrm{KC1}$, temperatures as indicated. Standard errors from nonlinear regression are given in parentheses.

well described by eq 5 . The $\mathrm{p} K_{\mathrm{a}}$ and limiting $k_{\text {cat }} / K_{\mathrm{M}}$ values obtained from the nonlinear regression fits to eq 5 are given in Table 1. Due to an equilibrium isotope effect on proton dissociation, the exchange of $\mathrm{H}_{2} \mathrm{O}$ for $\mathrm{D}_{2} \mathrm{O}$ produces an upward shift in the observed $\mathrm{p} K_{\mathrm{a}}$ values. The observed $\Delta \mathrm{p} K_{\mathrm{a}}$ values at $25{ }^{\circ} \mathrm{C}$ are 0.34 and 0.68 for the acidic and basic ionizations, respectively. These values are in the characteristic range for weak organic acids, which have $\Delta \mathrm{p} K_{\mathrm{a}}$ values of $0.5+0.2(38)$.

The $k_{\text {cat }} / K_{\mathrm{M}} \mathrm{pH}$ profile for serine is also shown in Figure $2 \mathrm{~A}$. Serine is 460 -fold worse as a substrate than is alanine based on the limiting values of $k_{\mathrm{cat}} / K_{\mathrm{M}}$ obtained from the $\mathrm{pH}$ profiles (Table 1). The acidic $\mathrm{p} K_{\mathrm{a}}$ value for the serine profile is, within error, very close to that for the alanine profile, while the basic $\mathrm{p} K_{\mathrm{a}}$ value is reduced by $\sim 1$ unit. This suggests that the basic ionization is due to the substrate $\alpha$-amino group, since serine has a 0.7 unit lower $\mathrm{p} K_{\mathrm{a}}$ value.
The $\mathrm{pL}$ profiles for alanine at $65^{\circ} \mathrm{C}$ are shown in Figure 2B. Similar bell-shaped curves are observed and the $\mathrm{p} K_{\mathrm{a}}$ values for $\mathrm{H}_{2} \mathrm{O}$ are reported in Table 1 . The observed $\mathrm{p} K_{\text {a }}$ values for the $\mathrm{D}_{2} \mathrm{O}$ profile at $65^{\circ} \mathrm{C}$ are $6.8 \pm 0.2$ and 10.0 \pm 0.2 . These values are not comparable to the other $\mathrm{p} K_{\mathrm{a}}$ values since no $\mathrm{pH}$ meter correction was available for 65 ${ }^{\circ} \mathrm{C}$ and uncorrected meter readings were used. These will remain uninterpreted due to this uncertainty. They are given here for completeness. Nonetheless, the profile fully serves the purpose of determining the apparent $\mathrm{pH}$ value required to obtain enzyme in equivalent protonation states in $\mathrm{H}_{2} \mathrm{O}$ and $\mathrm{D}_{2} \mathrm{O}$.

On the basis of the $\mathrm{H}_{2} \mathrm{O}$ data presented in Figure 2A and $\mathrm{B}$, the $\Delta H$ values for the two ionizations can be calculated. These are $6.5 \pm 0.4$ and $10.5 \pm 0.7 \mathrm{kcal} / \mathrm{mol}$ for the acidic and basic ionizations, respectively. The former compares favorably to a $\Delta H_{\text {ion }}$ of $6 \mathrm{kcal} / \mathrm{mol}$ for tyrosine (36) and 5.6 $\mathrm{kcal} / \mathrm{mol}$ for phenol (39) suggesting that the first ionization might be ascribed to Tyr265. The latter compares favorably to the $\Delta H_{\text {ion }}$ of $10.9 \mathrm{kcal} / \mathrm{mol}$ for alanine (36) and $10-13$ $\mathrm{kcal} / \mathrm{mol}$ for amino groups in general (39).

Multiple KIE Determinations. The excellent fits of bell shaped curves (eq 5) to the $k_{\text {cat }} / K_{\mathrm{M}} \mathrm{pL}$ profiles indicate that two ionizable groups control the rate of the enzymatic reaction. The deuterated and protiated forms of the enzyme/ substrate pair must be in the same ionic state to obtain accurate isotope effects, due to the influence of enzyme and substrate ionizations on commitment factors (34). The $\mathrm{p} K_{\mathrm{a}}$ values in Table 1 allow one to calculate the $\mathrm{pL}$ values at which the enzyme is in equivalent protonation states in $\mathrm{H}_{2} \mathrm{O}$ and $\mathrm{D}_{2} \mathrm{O}$. These were calculated to be 8.48 and 8.90 for $\mathrm{H}_{2} \mathrm{O}$ and $\mathrm{D}_{2} \mathrm{O}$, respectively, at $25{ }^{\circ} \mathrm{C}$.

Precise kinetic isotope effects in reversible enzyme catalyzed reactions can be measured using the equilibrium perturbation technique (26). In this method, the reactant and product concentrations are set at their equilibrium values, with one of the species containing a heavy atom substitution. The system is thus at "chemical" but not "isotopic" equilibrium. The difference in reaction rate between the light and heavy isotopes produces a transient perturbation away from the equilibrium concentrations, from which the KIE on $k_{\text {cat }} / K_{\mathrm{M}}$ can be calculated (26).

Alanine racemase presents a more complicated kinetic system. Here, one KIE is engendered by solvent deuteration and the other by alanine deuteration at $\mathrm{C} \alpha$. The latter site on both isomers is eventually fully equilibrated with the large pool of solvent isotope since: (i) the antipodal aldimine is formed through donation of a solvent derived hydron from one acid/base catalyst in a two-base mechanism (19), and (ii) washout of the original hydron from the second acid/ base catalyst into solvent is relatively rapid (40). This is illustrated in the upper panel of Figure 3 for the $\mathrm{H}_{2} \mathrm{O}$ case.

This incorporation of solvent derived isotope into the reactant and product pools creates multiple kinetic manifolds (Figure 3). A perturbation in this case can be obtained from rate differences between the two kinetic manifolds, which is the origin of the racemization "overshoot" phenomenon originally observed with proline racemase (41). The system eventually relaxes to a single manifold of solvent hydron composition. Thus, the reactant with isotopic composition initially different than that of solvent is the fractionating species. This would be the deuterated $\mathrm{D}$ isomer in $\mathrm{H}_{2} \mathrm{O}$ as 
A Competitive Deuterium Washout in $\mathrm{H}_{2} \mathrm{O}$

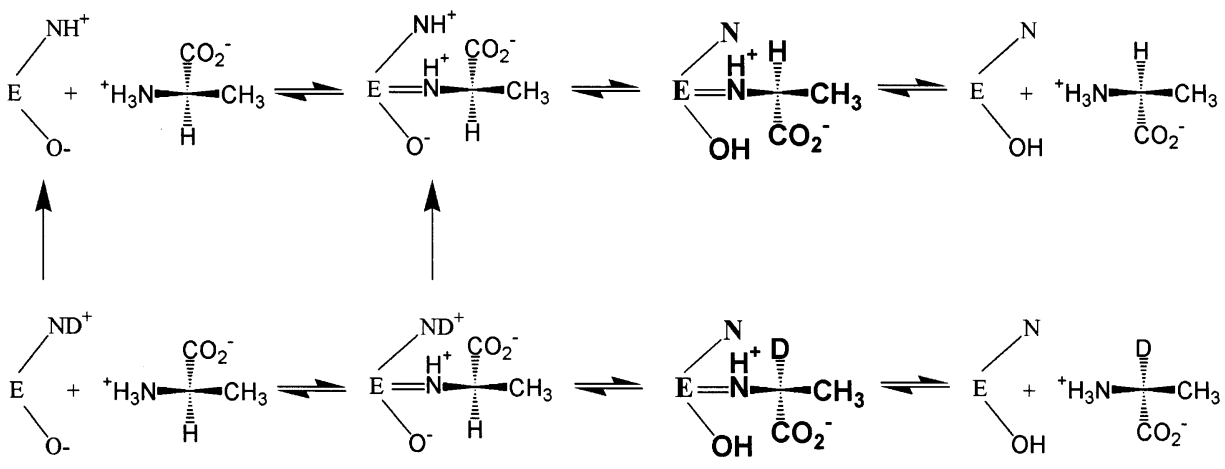

B Competitive Protium Washout in $\mathrm{D}_{2} \mathrm{O}$

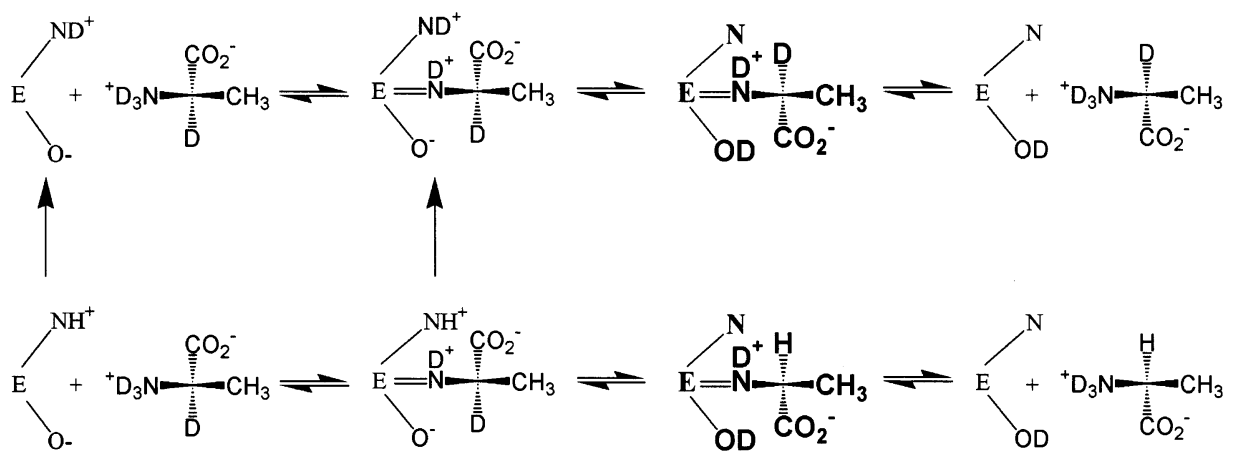

FIGURE 3: Schematic representations of D-alanine equilibrium perturbation-type washout experiments. (A) Washout of deuterated D-alanine in $\mathrm{H}_{2} \mathrm{O}$ from equal starting concentrations of $\left[{ }^{2} \mathrm{H}\right]$-D-alanine and $\left[{ }^{1} \mathrm{H}\right]$-L-alanine. At initiation of the perturbation, only the $\left[{ }^{2} \mathrm{H}\right]$-D-alanine (lower manifold) and $\left[{ }^{1} \mathrm{H}\right]$-L-alanine enzyme complexes (upper manifold) are present. The D isomer is transiently accumulated, due to slower racemization caused by the heavier isotope. The deuteron in $\left[{ }^{2} \mathrm{H}\right]$-D-alanine is washed out into the solvent pool during the course of racemization. At equilibrium, only the upper manifold exists, in which forward and reverse racemization rates are equal. The primary substrate KIE is due to the difference in rates of racemization of the $\left[{ }^{2} \mathrm{H}\right]-$ and $\left[{ }^{1} \mathrm{H}\right]-\mathrm{D}-$ alanine enzyme complexes, shown in bold. (B) Washout of $\left[{ }^{1} \mathrm{H}\right]$-D-alanine in $\mathrm{D}_{2} \mathrm{O}$ from equal starting concentrations of $\left[{ }^{1} \mathrm{H}\right]$-D-alanine and $\left[{ }^{2} \mathrm{H}\right]-\mathrm{L}$-alanine. The multiple kinetic isotope effect is obtained by comparing the magnitudes of the KIEs from the $\mathrm{H}_{2} \mathrm{O}$ and $\mathrm{D}_{2} \mathrm{O}$ perturbations.

drawn in the upper panel of Figure 3. This requires that the $\mathrm{D}$ isomer in $\mathrm{D}_{2} \mathrm{O}$ (lower panel of Figure 3 ) be protiated for it to fractionate.

In the $\mathrm{H}_{2} \mathrm{O}$ case, the initially deuterated (fractionating) isomer reacts slower than the protiated isomer, giving a transient accumulation of the fractionating isomer. In the $\mathrm{D}_{2} \mathrm{O}$ case, the initially protiated (fractionating) isomer reacts faster than the deuterated isomer, giving a transient accumulation of nonfractionating isomer. The perturbations for a given fractionating isomer in $\mathrm{H}_{2} \mathrm{O}$ vs $\mathrm{D}_{2} \mathrm{O}$ will thus be of opposite directions. This prediction is borne out by the experimental data presented in Figure 4.

Table 2 presents multiple KIEs obtained for both D- and L-isomers. In all cases, the primary substrate KIE is decreased by solvent deuteration. This is diagnostic for a stepwise mechanism (25). Table 3 compares the observed SIEs, obtained under the same conditions as the perturbations, to the SIEs calculated from the reduction in the substrate derived KIEs using eq $6(25)$. Here, ${ }_{2}{ }_{2} \mathrm{O}(V / K)_{\mathrm{D}}$ is the substrate

$$
\mathrm{SIE}=\frac{\left[{ }^{\mathrm{H}_{2} \mathrm{O}}(V / K)_{\mathrm{D}}-1\right]}{\left[{ }^{\mathrm{D}_{2} \mathrm{O}}(V / K)_{\mathrm{D}}-1\right]}
$$

derived $\mathrm{KIE}$ in $\mathrm{H}_{2} \mathrm{O}$, while $\mathrm{P}_{2} \mathrm{O}(V / K)_{\mathrm{D}}$ is the substrate derived

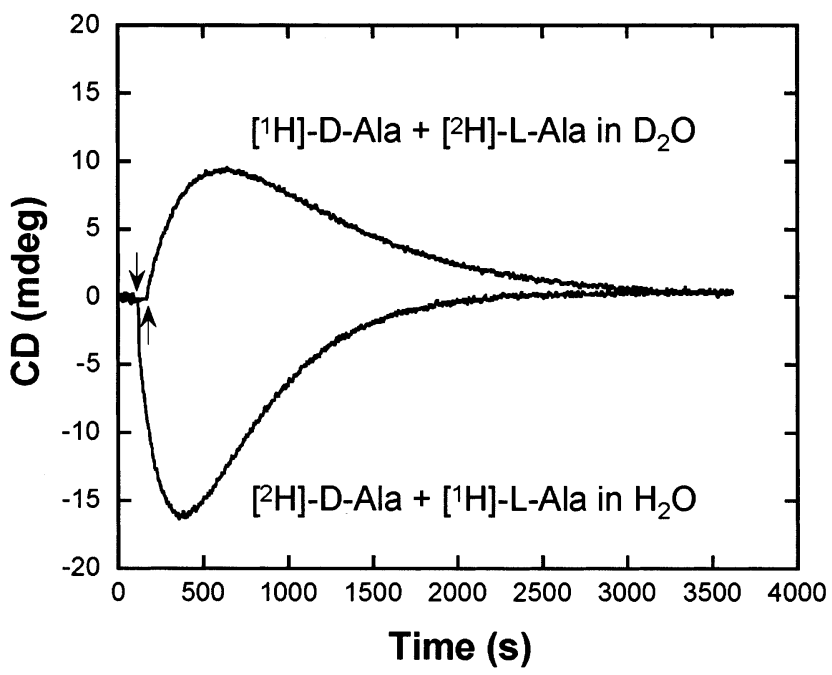

FIGURE 4: Equilibrium perturbation-type washout experiments. The isotopic compositions of the reactants are indicated. At $25^{\circ} \mathrm{C}, \mathrm{H}_{2} \mathrm{O}$ solutions were $\mathrm{pH} 8.48$ and $\mathrm{D}_{2} \mathrm{O}$ solutions were $\mathrm{pD} 8.90$, which gives enzyme in the same ionic state.

$\mathrm{KIE}$ in $\mathrm{D}_{2} \mathrm{O}$. The observed and calculated SIEs are in excellent agreement. The larger SIE in the $\mathrm{D} \rightarrow \mathrm{L}$ direction elicits a larger reduction in the substrate derived KIE than that observed in the $\mathrm{L} \rightarrow \mathrm{D}$ direction. 
Table 2: Multiple Kinetic Isotope Effects from Equilibrium Perturbation-Type Experiments ${ }^{a}$

\begin{tabular}{cccccc}
\hline \multirow{2}{*}{$\begin{array}{c}\text { fractionating } \\
\text { isomer }\end{array}$} & \multicolumn{2}{c}{$25^{\circ} \mathrm{C}^{b}$} & & \multicolumn{2}{c}{$65^{\circ} \mathrm{C}^{c}$} \\
\cline { 2 - 3 } \cline { 5 - 6 } \cline { 5 - 6 } D-alanine & $1.297(0.012)$ & $1.176(0.004)$ & & $1.355(0.005)$ & $1.265(0.002)$ \\
L-alanine & $1.877(0.007)$ & $1.824(0.006)$ & & $1.491(0.006)$ & $1.486(0.009)$ \\
\hline
\end{tabular}

${ }^{a}$ Perturbations were treated as in Bahnson and Anderson (29) in which hydron washout is considered irreversible. The KIEs represent averages of triplicate determinations. Standard deviations for replicate measurements are given in parentheses. ${ }^{b} \mathrm{H}_{2} \mathrm{O}$ solutions were at $\mathrm{pH}$ 8.48 and $\mathrm{D}_{2} \mathrm{O}$ solutions were at $\mathrm{pD} 8.90$, which correspond to the same ionic state of the enzyme, indicated by the data in Figure $2 \mathrm{~A} .{ }^{c}$ At 65 ${ }^{\circ} \mathrm{C}, \mathrm{H}_{2} \mathrm{O}$ solutions were at $\mathrm{pH} 8.0$ and $\mathrm{D}_{2} \mathrm{O}$ solutions had a $\mathrm{pH}$ meter reading of 8.4, which corresponds to the same ionic state of the enzyme, indicated by the data in Figure 2B.

Table 3. Observed and Calculated $k_{\text {cat }} / K_{\mathrm{M}}$ Solvent Isotope Effects

\begin{tabular}{llllll}
\hline & \multicolumn{2}{c}{$25^{\circ} \mathrm{C}^{b}$} & & \multicolumn{2}{c}{$65^{\circ} \mathrm{C}^{c}$} \\
\cline { 2 - 3 } \cline { 5 - 6 } \cline { 5 - 6 } & $\mathrm{D} \rightarrow \mathrm{L}$ & $\mathrm{L} \rightarrow \mathrm{D}$ & & $\mathrm{D} \rightarrow \mathrm{L}$ & $\mathrm{L} \rightarrow \mathrm{D}$ \\
\hline $\begin{array}{l}\text { SIE calculated } \\
\text { for stepwise } \\
\quad \text { mechanism }\end{array}$ & 1.69 & 1.07 & & 1.35 & 1.01 \\
$\begin{array}{l}\text { SIE from } \\
\text { progress } \\
\text { curves }\end{array}$ & $1.63(0.09)$ & $1.06(0.08)$ & & $1.30(0.09)$ & $1.02(0.05)$ \\
\hline
\end{tabular}

${ }^{a}$ Calculated from the two primary effects in Table 1 assuming a stepwise mechanism, as described by O'Leary $(25) .{ }^{b} \mathrm{H}_{2} \mathrm{O}$ data was obtained at $\mathrm{pH} 8.48$, while $\mathrm{D}_{2} \mathrm{O}$ runs were at a $\mathrm{pD}$ of 8.90 , which corresponds to the same ionic state of the enzyme. Standard deviations for replicate measurements are given in parentheses. ${ }^{c}$ At $65{ }^{\circ} \mathrm{C}, \mathrm{H}_{2} \mathrm{O}$ data was obtained at $\mathrm{pH} 8.0$, while $\mathrm{D}_{2} \mathrm{O}$ runs had a $\mathrm{pH}$ meter reading of 8.4, which corresponds to the same ionic state of the enzyme. Standard deviations for replicate measurements are given in parentheses.

Table 2 also presents multiple KIEs obtained for both D and $\mathrm{L}$ isomers at $65^{\circ} \mathrm{C}$. The changes in the KIEs are smaller than for $25{ }^{\circ} \mathrm{C}$, and the $\mathrm{D} \rightarrow \mathrm{L}$ direction gives the only statistically significant change; a reduction of the substrate $\mathrm{KIE}$ in $\mathrm{D}_{2} \mathrm{O}$ is observed. The multiple KIE diagnosis for 65 ${ }^{\circ} \mathrm{C}$ is thus the same as for $25^{\circ} \mathrm{C}$, a stepwise mechanism. Table 3 shows that the experimental SIE for the $\mathrm{D} \rightarrow \mathrm{L}$ direction at $65^{\circ} \mathrm{C}$ agrees well with that calculated from the reduction in the substrate $\mathrm{KIE}$.

\section{DISCUSSION}

Stepwise Double Proton-Transfer Catalyzed by Two Acid/ Base Catalysts. The dependence of a KIE on the isotopic composition of a second site has been applied as a diagnostic for stepwise vs. concerted bond making/breaking steps in a number of enzyme catalyzed reactions $(23,24,42,43)$. This multiple KIE type of experiment requires the prior observation of two independent KIEs. In the case of alanine racemase, two independent hydrogen KIEs were previously measured using initial rate techniques (19). These were obtained in separate experiments using alanine deuterated at $\mathrm{C} \alpha$, and $\mathrm{D}_{2} \mathrm{O}$. The observation of two independent KIEs opens the possibility that both isotopes are being transferred in the same transition state, i.e., in a concerted double proton transfer.

The X-ray structure of alanine racemase shows that two active site residues are well positioned to act as acid/base catalysts. These are Tyr265 and Lys39, which lie on opposite faces of and close to $\mathrm{C} \alpha$ in the external aldimine formed from alanine phosphonate (44) and in the two isomeric phosphopyridoxylalanine structures (45). It has been demonstrated by mutagenesis that these are the two acid/base catalysts in a two-base racemization mechanism. Watanabe et al. (46) showed that the Y265A mutant is 1000-fold less active than the wild-type enzyme, while the K39A mutant was shown to be completely inactive but is rescued by the addition of methylamine (21). Mutants at $\operatorname{Arg} 219$, which hydrogen bonds to the pyridine nitrogen of PLP, have also been characterized (19). This latter work showed that the hydrogen bond to the pyridine nitrogen is worth only 40fold to the catalytic mechanism based on limiting $k_{\text {cat }} / K_{\mathrm{M}}$ values from $\mathrm{pH}$ profiles. The lowering of the Tyr265 phenolic hydroxyl $\mathrm{p} K_{\mathrm{a}}$ from $\sim 10$ to $\sim 7$ via interaction through His 166 is the major role of this residue. Thus, a two-base mechanism for alanine racemization, employing Lys39 and Tyr265, is well established, which is a requirement for a concerted double proton transfer.

Evidence disfavoring a stepwise mechanism has also been obtained. The quinonoid resonance form $\left(\lambda_{\max } \sim 500 \mathrm{~nm}, \epsilon\right.$ $\sim 40000 \mathrm{M}^{-1} \mathrm{~cm}^{-1}$ ) of a carbanionic intermediate, which is central to a stepwise mechanism, is not observed with the wild-type enzyme either in stopped-flow experiments (19), or in static experiments in which $50 \mathrm{mM}$ (saturating) of each D- and L-alanine were added to $50 \mu \mathrm{M}$ wild type subunits (data not shown). These data allow one to calculate that the quinonoid carbanionic intermediate is $\geq 4.5 \mathrm{kcal} / \mathrm{mol}$ higher in energy than the aldimine intermediates. Yet, with the R219E mutant quinonoid absorbance is readily observed (19), as it is with the R219A mutant containing $N$-methylPLP (Toney, unpublished results).

The magnitude of the primary substrate and solvent KIEs measured previously with alanine racemase $(\sim 1.5)$ are both small (19). This requires the use of a high precision technique for measuring the multiple KIEs, since the expected decrease in the first KIE by substitution at the second site would be smaller than could be accurately determined by routine steady-state techniques. Published methods for high precision steady-state kinetic studies were cost prohibitive for the present study due to coupling enzyme costs (47).

Given the reversibility of the alanine racemase catalyzed reaction, the equilibrium perturbation technique (26) appeared suited to the purpose. Bahnson and Anderson (29) provide a straighforward theoretical treatment of equilibrium perturbation-type experiments where a substrate derived hydron is irreversibly lost to solvent during the course of the reaction, as is the case with alanine racemase. Fisher et al. (30) also treated such a system, but, to the present authors, their analysis is much less accessible than that of Bahnson and Anderson.

The primary substrate KIE for a single reaction direction (e.g., D $\rightarrow$ L) can be obtained from equilibrium perturbationtype washout experiments (29). Thus, one can perform multiple KIE analyses by measuring the effect of substitution of $\mathrm{D}_{2} \mathrm{O}$ for $\mathrm{H}_{2} \mathrm{O}$ on the primary substrate KIE. At the risk of being redundant of the explanation given in Results, the following attempts to provide a qualitative understanding of the equilibrium perturbation-type experiments required to obtain the multiple KIEs.

The primary substrate $\mathrm{KIE}$ measurement in $\mathrm{H}_{2} \mathrm{O}$ is conceptually straightforward. If, as is shown in Figure 3, the $\mathrm{D}$ isomer is initially deuterated and the $\mathrm{L}$ isomer is 
protiated, the $\mathrm{L}$ isomer reacts faster to $\mathrm{D}$ than does the $\mathrm{D}$ isomer to $\mathrm{L}$ if a primary substrate KIE is expressed on the $\mathrm{D}$ $\rightarrow \mathrm{L}$ reaction. If no deuterium were present in the $\mathrm{D}$ isomer initially, then no perturbation from equilibrium (i.e., deviation from zero optical rotation in these experiments) would be observed when enzyme is added.

The primary substrate KIE measurement in $\mathrm{D}_{2} \mathrm{O}$ is not as conceptually straightforward. Simply changing the solvent from $\mathrm{H}_{2} \mathrm{O}$ to $\mathrm{D}_{2} \mathrm{O}$ in the above experiment in which the $\mathrm{D}$ isomer is initially deuterated does not yield the desired KIE. In this case, the D isomer remains deuterated throughout the course of the reaction since deuterium is provided by solvent for incorporation into D isomer that is produced from L. On the other hand, the $\mathrm{L}$ isomer will not remain protiated during the course of the reaction, but will eventually become fully deuterated. As $\mathrm{L}$ is converted to $\mathrm{D}$, the substrate derived proton is lost to solvent by exchange and the nascent $\mathrm{D}$ isomer acquires a deuteron from solvent. Eventually, an all deuterated equilibrium is reached. In this case, isotopic discrimination is determined by the nonsolvent isotope that is present initially but lost to solvent at equilbrium, i.e., the protium on the $\mathrm{L}$ isomer.

The primary substrate KIE for the $\mathrm{D}$ isomer fractioning in $\mathrm{D}_{2} \mathrm{O}$, required for the multiple KIE comparison to deuterated D isomer in $\mathrm{H}_{2} \mathrm{O}$, is thus obtained by employing initially protiated $\mathrm{D}$ isomer in $\mathrm{D}_{2} \mathrm{O}$. This reacts faster than the deuterated $\mathrm{L}$ isomer in the reverse reaction due to the primary KIE in the $\mathrm{D} \rightarrow \mathrm{L}$ direction. The signs of the perturbations will be opposite since in $\mathrm{H}_{2} \mathrm{O}$ the $\mathrm{D}$ isomer accumulates transiently while in $\mathrm{D}_{2} \mathrm{O}$ the $\mathrm{L}$ isomer accumulates transiently, even though the same primary KIE is being measured. This remarkable prediction is observed experimentally as shown by the data in Figure 4.

With an understanding of the required experiments in hand, the collection of the data was straightforward and high precision was obtained from triplicate measurements. The multiple KIE data presented in Table 2 provide strong evidence that alanine racemase employs a stepwise not a concerted mechanism for the two proton transfers required to effect racemization of the external aldimine intermediate. The data for the $\mathrm{D} \rightarrow \mathrm{L}$ direction at $25^{\circ} \mathrm{C}$ show a reduction of $\sim 10 \%$ in the primary KIE, well outside the error of the determinations. The KIE reductions for the $\mathrm{L} \rightarrow \mathrm{D}$ direction are smaller but nonetheless statistically significant.

The enzyme employed in this study is from B. stearothermophilus, a thermophilic bacterium whose optimal growth temperature is $\sim 65^{\circ} \mathrm{C}$. Thus, the multiple KIEs were measured at this higher temperature also to probe the mechanism at the temperature to which the enzyme has been adapted, as a comparison to the "cold" regime of $25^{\circ} \mathrm{C}$. Again, a reduction of the primary substrate KIE of $\sim 10 \%$ is observed for the $\mathrm{D} \rightarrow \mathrm{L}$ direction, supporting a stepwise mechanism at this higher temperature. The KIE change in the $\mathrm{L} \rightarrow \mathrm{D}$ direction is not statistically significant at $65^{\circ} \mathrm{C}$. Apparently, alanine racemase preserves its basic chemical mechanism, as well as its free energy profile as gleaned from the similar KIEs, over this $40{ }^{\circ} \mathrm{C}$ temperature range.

The formation of the external aldimine from the internal aldimine plus substrate requires at least two proton-transfer steps (see below). Thus, it is possible that the SIEs observed with alanine racemase are due to one of these proton transfers that are not involved in the stereoisomerization step. If this were the case, then the observed reduction in primary substrate KIEs would not be indicative of a stepwise interconversion of stereoisomeric aldimines, rather it would simply be due to an increase in the appropriate commitment factor due to solvent substitution in transimination.

The following reasoning suggests that internal/external aldimine interchange is not significantly rate limiting under the present conditions, and that the interpretation of the multiple KIEs as supporting a stepwise mechanism is correct. Linear proton inventories on $\mathrm{k}_{\text {cat }}(\mathrm{KIEs} \sim 1.5)$ were observed in both directions for the wild-type enzyme, indicating a single solvent derived proton in flight in the solvent sensitive step that occurs after enzyme-substrate complexation in either reaction direction (19). This proton was assumed to be the one being donated to $\mathrm{C} \alpha$ in stereoisomerization in the above discussion. This assumption is supported by the fact that, in both directions, primary substrate KIEs on $k_{\text {cat }}$ and $k_{\text {cat }} / K_{\mathrm{M}}$ are significant and similar $(\sim 1.5)$ (19). The solvent derived proton being transferred to $\mathrm{C} \alpha$ in one direction (e.g., $\mathrm{D} \rightarrow \mathrm{L}$ ) is mechanistically equivalent to the substrate derived proton in the other direction (e.g., $\mathrm{L} \rightarrow \mathrm{D}$ ), and this solvent derived proton must be that observed in the proton inventories given the substrate KIEs. Additional evidence that weighs against this possibility is the observation that the wild-type enzyme shows no dependence on solvent viscosity at pH 8.9 (Toney et al., unpublished results).

The high specificity of alanine racemase for racemization vs transamination (31) would be cleanly explained by a concerted double proton transfer were it enforced. In the context of a stepwise mechanism, the relative destabilization of the carbanionic quinonoid intermediate by employing Arg219 to interact with the PLP pyridine nitrogen instead of an aspartate or glutamate at this position would also tend to disfavor transamination or other side reactions. Transamination, for example, requires a 1,3-prototropic shift from $\mathrm{C} \alpha$ to $\mathrm{C}^{\prime}$. This requires a relatively long quinonoid lifetime to be efficient, such that the acid/base catalyst can move to deliver the proton to the second site. The shorter lifetime of the carbanionic intermediate in alanine racemase, coupled with the prepositioning of the proton donor on the opposite face of $\mathrm{C} \alpha$, would tend to favor 1,1-proton transfer as occurs in racemization.

Protonation States of Catalytically Productive Enzyme and Substrate. The mechanisms of PLP-dependent enzymes require the formation of a covalent substrate-coenzyme Schiff base (external aldimine intermediate). This is formed via a transimination reaction in which, ultimately, a protonated Lys-PLP Schiff base (internal aldimine) is attacked by a deprotonated substrate amino group. Interestingly, it was shown that with aspartate aminotransferase this can occur by either of two routes (48). The unprotonated internal aldimine enzyme can bind the protonated amino acid substrate, with subsequent proton transfer between these to get the reactive form. Alternatively, the protonated enzyme can bind the unprotonated substrate, with direct reaction between these to form the external aldimine.

Alanine racemase exists only in the form in which the Lys39-PLP Schiff base is protonated from $\mathrm{pH} 6-10.5$, since no spectral changes in the coenzyme spectra are observed over this $\mathrm{pH}$ range (data not shown). Thus, either the unprotonated substrate must be captured by the enzyme for 

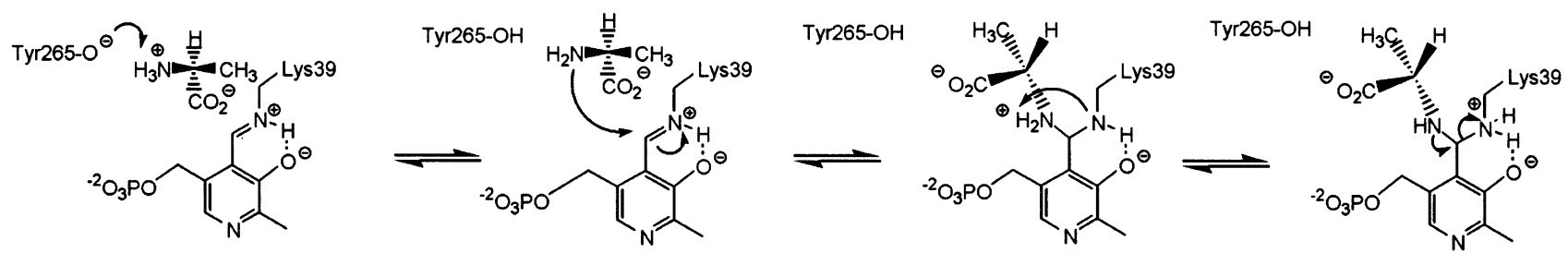

D-Alanine Michaelis Complex
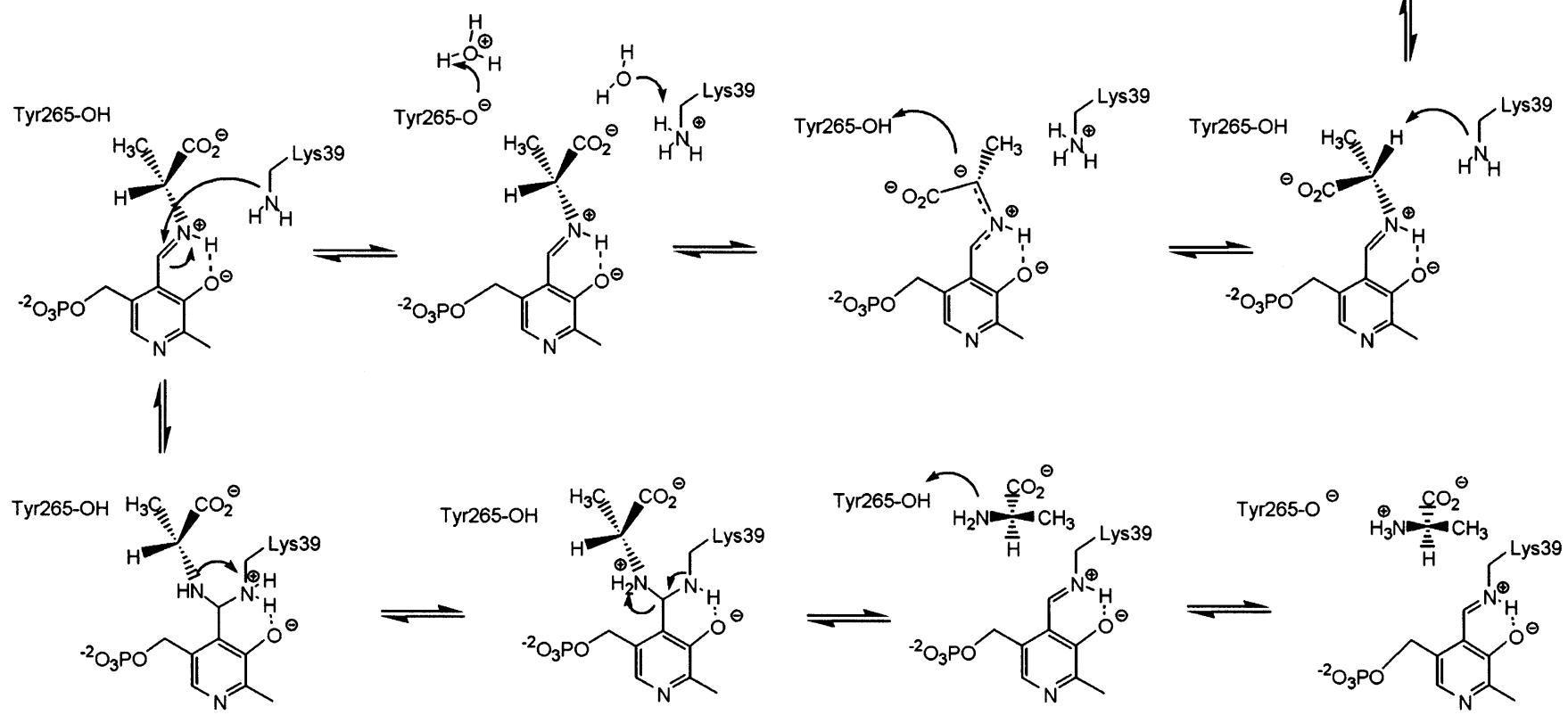

L-Alanine Michaelis Complex

FIGURE 5: Detailed mechanism for the alanine racemase catalyzed reaction. For simplicity, proton exchanges at Lys39 and Tyr265 are shown to occur from the same intermediate. This is not a necessity.

reaction to occur, or an active site residue in its basic form must deprotonate the predominantly protonated amino acid substrate near neutral $\mathrm{pH}$ values.

Previous mutagenesis and isotope studies (19) showed that $\operatorname{Arg} 219$ lowers the $\mathrm{p} K_{\mathrm{a}}$ of an active site residue responsible for the acidic limb of the bell shaped $k_{\mathrm{cat}} / K_{\mathrm{M}} \mathrm{pH}$ profile of the wild type enzyme. This is expected to be Tyr265 based on its known role as an acid/base catalyst and its electrostatic connection to Arg219 through His166. The ionization controlling the basic limb was more difficult to assign. The coincidence of the higher $\mathrm{p} K_{\mathrm{a}}$ value with that of the free substrate was suggestive, yet mutations at Arg219 apparently increased this $\mathrm{p} K_{\mathrm{a}}$ weighing against it being the substrate.

The data presented here allow clean assignments of the two ionizations observed in the $k_{\mathrm{cat}} / K_{\mathrm{M}} \mathrm{pH}$ profile for wild type. The $\mathrm{p} K_{\mathrm{a}}$ values obtained at different temperatures allow the calculation of the $\Delta H_{\text {ion }}$ values, while the use of serine as an alternative substrate allows perturbation of the $\mathrm{p} K_{\mathrm{a}}$ value of the substrate $\alpha$-amino group. The $\Delta H_{\text {ion }}$ value for the acidic $\mathrm{p} K_{\mathrm{a}}$ is very close to that observed for free tyrosine and phenol. This further supports the prior assignment of Tyr265 as the residue responsible for this ionization. The basic $\mathrm{p} K_{\mathrm{a}}$ has a $\Delta H_{\text {ion }}$ that is consistent with it being an amino group, either the substrate or Lys39 in the internal aldimine since PLP aldimine $\Delta H_{\text {ion }}$ values are also $\sim 10 \mathrm{kcal} / \mathrm{mol}(49)$. Due to the $\beta$-hydroxyl group, serine has a substantially lower $\mathrm{p} K_{\mathrm{a}}$ than alanine, and is a reasonably good (460-fold less active) substrate compared to alanine. The serine $k_{\text {cat }} / K_{\mathrm{M}} \mathrm{pH}$ profile was thus measured and the $\mathrm{p} K_{\mathrm{a}}$ values obtained show an unaltered (within experimental error) acidic $\mathrm{p} K_{\mathrm{a}}$ and a substantially lowered basic $\mathrm{p} K_{\mathrm{a}}$ value, equal to that of free serine. The combination of data (i.e., perturbed acidic $\mathrm{p} K_{\mathrm{a}}$ values with R219 mutants, internal aldimine ionization not observed in spectral titrations of wild type, $\Delta H_{\text {ion }}$ values, and $\mathrm{p} K_{\mathrm{a}}$ values from alanine and serine $\mathrm{pH}$ profiles) demonstrate that the acidic $\mathrm{p} K_{\mathrm{a}}$ is due to Tyr265 and the basic $\mathrm{p} K_{\mathrm{a}}$ is due to the $\alpha$-amino group of the amino acid substrate.

The initial productive interaction between alanine racemase and either isomer of alanine must then occur between an enzyme with the Lys39-PLP Schiff base protonated and Tyr265 unprotonated, and a substrate whose $\alpha$-amino group is protonated, which is the predominant form at physiological $\mathrm{pH}$. An active site residue must deprotonate the amino acid before it can attack the protonated Lys39-PLP Schiff base. On the basis of the active site structure of the enzyme, Tyr265 is likely to fulfill this role.

Figure 5 gives a detailed mechanism that incorporates these conclusions. After alanine binds and is deprotonated by Tyr265, it attacks the protonated Lys39-PLP Schiff base to give the gem-diamine intermediate which goes on to the external aldimine after a proton transfer. For both isomers, the external aldimine initially formed has Lys39 unprotonated and Tyr265 protonated. This is the protonation state that is catalytically active for $\mathrm{D} \rightarrow \mathrm{L}$ isomerization. If the substrate is the $\mathrm{L}$ isomer, proton transfers at Tyr265 and Lys 39 must occur before stereoisomerization of the external aldimine intermediate can occur. Watanabe et al. (45) proposed proton transfer between Tyr265 and Lys39 as an intrinsic component 
of a mechanism in which a protonated $\alpha$-carboxyl is employed. This is an unusual proposition since the substrate carboxylate is stabilized by hydrogen bonds from the side chain guanidino group of Arg136 and from the main chain amide of Met312 (50). Given the large number of examples of enzyme catalyzed reactions in which protons are rapidly exchanged from reaction intermediates, there is no mechanistic imperative to propose such a proton exchange/transfer mechanism. Rather, the mechanism in Figure 5 simply assumes that the dynamic water molecules and hydrogen bonding interactions in the active site allow rapid equilibration of active site protons with the solvent, based on their $\mathrm{p} K_{\mathrm{a}}$ values.

\section{REFERENCES}

1. Neidhart, F. C. (1999) Escherichia coli and Salmonella, 2nd ed.; Blackwell Publishing, London.

2. Walsh, C. T. (1989) J. Biol. Chem. 264, 2393-6.

3. Wood, W. A., and Gunsalus, I. C. (1951) J. Biol. Chem. 193, 403416.

4. Kollonitsch, J., Barash, L., Kahan, F. M., and Kropp, H. (1973) Nature 243, 346-7.

5. Duncan, K., Faraci, W. S., Matteson, D. S., and Walsh, C. T. (1989) Biochemistry 28, 3541-9.

6. Thornberry, N. A., Bull, H. G., Taub, D., Wilson, K. E., GimenezGallego, G., Rosegay, A., Soderman, D. D., and Patchett, A. A. (1991) J. Biol. Chem. 266, 21657-65.

7. Faraci, W. S., and Walsh, C. T. (1989) Biochemistry 28, 431-7.

8. Copie, V., Faraci, W. S., Walsh, C. T., and Griffin, R. G. (1988) Biochemistry 27, 4966-70.

9. Lambert, M. P., and Neuhaus, F. C. (1972) J. Bacteriol. 110, 97887.

10. Soper, T. S., and Manning, J. M. (1981) J. Biol. Chem. 256, 42638.

11. Wang, E., and Walsh, C. (1978) Biochemistry 17, 1313-21.

12. Peisach, D., Chipman, D. M., Van Ophem, P. W., Manning, J. M., and Ringe, D. (1998) Biochemistry 37, 4958-67.

13. Malashkevich, V. N., Strop, P., Keller, J. W., Jansonius, J. N., and Toney, M. D. (1999) J. Mol. Biol. 294, 193-200.

14. Wolinsky, E. (1993) Clin. Infect. Dis. 16, 627-8.

15. David, S. (2001) J. Antimicrob. Chemother. 47, 203-6.

16. Kuze, F., Kurasawa, T., Bando, K., Lee, Y., and Maekawa, N. (1981) Rev. Infect. Dis. 3, 885-97.

17. Peloquin, C. A. (1993) Med. Clin. North Am. 77, 1253-62.

18. Peloquin, C. A. (2002) Drugs 62, 2169-83.

19. Sun, S. X., and Toney, M. D. (1999) Biochemistry 38, 40584065.

20. Watanabe, A., Kurokawa, Y., Yoshimura, T., and Esaki, N. (1999) J. Biochem. 125, 987-990.

21. Watanabe, A., Kurokawa, Y., Yoshimura, T., Kurihara, T., Soda, K., and Esaki, N. (1999) J. Biol. Chem. 274, 30334.

22. Shaw, J. P., Petsko, G. A., and Ringe, D. (1997) Biochemistry 36, 1329-1342.

23. Hermes, J. D., Roeske, C. A., O’Leary, M. H., and Cleland, W. W. (1982) Biochemistry 21, 5106-14.
24. Belasco, J. G., Albery, W. J., and Knowles, J. R. (1986) Biochemistry 25, 2552-8.

25. O'Leary, M. H. (1989) Annu. Rev. Biochem. 58, 377-401.

26. Schimerlik, M. I., Rife, J. E., and Cleland, W. W. (1975) Biochemistry 14, 5347-54.

27. O'Leary, M. H., Northrop, D. B., and Cleland, W. W. (1977) Isotope Effects on Enzyme-Catalyzed Reactions: Proceedings of the Sixth Annual Harry Steenbock Symposium, University Park Press, Baltimore

28. Cleland, W. W. (1980) Methods Enzymol. 64, 104-25.

29. Bahnson, B. J., and Anderson, V. E. (1989) Biochemistry 28, 4173-81.

30. Fisher, L. M., Belasco, J. G., Bruice, T. W., Albery, W. J., and Knowles, J. R. (1986) Biochemistry 25, 2543-51.

31. Kurokawa, Y., Watanabe, A., Yoshimura, T., Esaki, N., and Soda, K. (1998) J. Biochem. 124, 1163-1169.

32. Segel, I. H. (1993) Enzyme Kinetics: Behavior and Analysis of Rapid Equilibrium and Steady-State Enzyme Systems, John Wiley \& Sons, Inc.

33. Moore, J. W., Pearson, R. G., and Frost, A. A. (1981) Kinetics and mechanism, 3rd ed., Wiley, New York.

34. Schowen, K. B., and Schowen, R. L. (1982) Methods Enzymol. $87,551-606$

35. Dawson, R. M. C., Elliot, D. C., Elliot, W. H., and Jones, K. M. (1986) Data for Biochemical Research, 3rd ed., Oxford University Press, Oxford, U.K.

36. Fasman, G. D. (1976) CRC Practical Handbook of Biochemistry and Molecular Biology, 3rd ed., CRC Press, Inc., Boca Raton, FL.

37. Patrick, W. M., Weisner, J., and Blackburn, J. M. (2002) Chembiochem 3, 789-92.

38. Jencks, W. P. (1969) Catalysis in Chemistry and Enzymology, McGraw-Hill, New York.

39. Isaacs, N. S. (1995) Physical Organic Chemistry, 2nd ed., Wiley and Sons, New York.

40. Faraci, W. S., and Walsh, C. T. (1988) Biochemistry 27, $3267-$ 76.

41. Cardinale, G. J., and Abeles, R. H. (1968) Biochemistry 7, 39708.

42. Grissom, C. B., and Cleland, W. W. (1988) Biochemistry 27, 2934-43.

43. Julin, D. A., and Kirsch, J. F. (1989) Biochemistry 28, 3825-33.

44. Stamper, C. G. F., Morollo, A. A., and Ringe, D. (1998) Biochemistry 37, 10438-10445.

45. Watanabe, A., Yoshimura, T., Mikami, B., Hayashi, H., Kagamiyama, H., and Esaki, N. (2002) J. Biol. Chem. 277, 1916672.

46. Watanabe, A., Yoshimura, T., Mikami, B., and Esaki, N. (1999) J. Biochem. 126, 781-786.

47. Zhou, X. Z., and Toney, M. D. (1998) J. Am. Chem. Soc. 120, $13282-13283$

48. Hayashi, H., and Kagamiyama, H. (1997) Biochemistry 36, $13558-69$.

49. Christen, P., and Metzler, D. E. (1985) Transaminases, Wiley, New York.

50. Morollo, A. A., Petsko, G. A., and Ringe, D. (1999) Biochemistry 38, 3293-301.

BI0274064 